\title{
Preface
}

\section{Subjective Cognitive Decline}

\author{
Andrea Tales ${ }^{\mathrm{a}, *}$, Frank Jessen $^{\mathrm{b}, \mathrm{c}}$, Christopher Butler $^{\mathrm{d}}$, Gordon Wilcock $^{\mathrm{d}}$, Judith Phillips ${ }^{\mathrm{e}}$ \\ and Tony Bayer ${ }^{\mathrm{f}}$ \\ ${ }^{a}$ College of Human and Health Sciences, Department of Psychology, Swansea University, Swansea, Wales, UK \\ ${ }^{\mathrm{b}}$ Department of Psychiatry, University of Cologne, Medical Faculty, Cologne, Germany \\ ${ }^{\mathrm{c}}$ German Center for Neurodegenerative Disorders (DZNE), Germany \\ ${ }^{\mathrm{d}}$ Nuffield Department of Clinical Neurosciences, University of Oxford, John Radcliffe Hospital, Oxford, UK \\ ${ }^{\mathrm{e}}$ Centre for Ageing and Dementia Research, Swansea University, Swansea, Wales, UK \\ ${ }^{\mathrm{f}}$ School of Medicine, Cardiff University, Wales, UK
}

Perceived decline in cognition in the absence of what is commonly termed 'objective evidence' is frequently referred to as subjective cognitive decline (SCD). While etiologically heterogeneous and therefore potentially responsive to intervention in some cases, SCD remains primarily associated with an increased risk of developing dementia. It is becoming clear however that, irrespective of cause, SCD can have a detrimental effect upon quality of life. Although there is increasing interest in SCD within both research and clinical arenas, it remains a topic that provokes substantial debate particularly with regard to its definition, diagnosis, and management.

The aim of this supplemental issue of the Journal of Alzheimer's Disease is to bring together some of these controversial areas of discussion in order to promote future debate and collaborative research about SCD and to encourage greater unity of approach. Consequently, the content of the articles presented here is varied and includes reviews, audits, perspectives, concepts, models, and research papers using qualitative and quantitative research methodologies.

Starting with a conceptual paper, Stone and colleagues [1] illustrate how SCD can arise from a range of 'functional' disorders, as well as in some cases being a harbinger of neurodegenerative dementia, and highlight the importance of correct classification.

\footnotetext{
*Correspondence to: Andrea Tales, College of Human and Health Sciences, Department of Psychology, Swansea University, Swansea SA2 8PP, Wales, UK. Tel.: +44 01792 205678; E-mail: A.Tales@swansea.ac.uk.
}

Moving on to audits, Pennington and colleagues [2] highlight and discuss the fact that functional memory disorders are common in neurology memory services; that patients with functional symptoms are not only the worried well or just suffering from anxiety and depression, and that there can be significant social and occupational impairment. Of particular relevance to memory clinics and services is the qualitative service evaluation performed by Jenkins and colleagues [3] to determine the state of knowledge of SCD and what actions are taken for its management in specialist clinical practice in the UK at the present time.

Related to the potential real life impact of SCD is the finding by Luck and colleagues [4] of a significantly increased mortality risk in non-demented elderly people with SCD. This highlights the importance of taking SCD seriously in clinical practice not only in relation to an increased risk of developing dementia but also for a broader range of possible adverse health outcomes, one of which may be mortality.

In terms of assessment, Tandetnik and colleagues [5] highlight how variability in assessment method, specifically the manner in which questions and response options are phrased, plays an important role in determining rates of SCD. Also related to assessment is Della Barba and colleagues' [6] model suggesting that the neuropsychological assessment of memory performance should always be coupled with a deep evaluation of awareness of the individual's memory profile. An in-depth review by Rabin and colleagues [7] describes the self-report measures currently employed by 19 international sites and calls for international 
collaboration to promote harmonization and pooling of cognitive self-report data. Valech and colleagues [8] describe a study in which they found that informants' ratings of cognitive decline were able to differentiate pre-Alzheimer's disease (AD) subjects from controls and that informants' ratings also correlated significantly with AD biomarkers. Rodríguez-Gómez and colleagues [9] show that the setting in which the study is conducted affects key characteristics of the sample such as age, educational level, or family history and discuss the paucity of studies that specifically test the influence of sampling and recruitment methods in this area of research.

On the topic of etiology, Archer and colleagues [10] describe how SCD in some individuals will result from mood disorders/personality factors or systemic illness; evaluating how individuals are defined within different research settings, their rates of progression to mild cognitive impairment and dementia, and how individuals within these contexts differ in terms of complaints, personal characteristics, and help seeking behavior. Also related to the issue of mood disorders is the study by Yates and colleagues [11], who, using structured interviews with community dwelling older people to collect information regarding cognitive functioning, mood, and wellbeing, reveal that subjective memory complaints are more likely to be related to mood problems than objective cognitive impairment. Continuing this theme, Buckley and colleagues [12] describe how that although the presence of SCD is acknowledged as a risk factor of future dementia, few studies have attempted to capture the qualitative perspective of this phenomenological experience, pointing out that such a perspective is often central to clinical diagnostics, and therefore potentially of use in determining the underlying cause of SCD.

A neuroimaging study by Perrotin and colleagues [13] investigates hippocampal subfields for the first time in SCD using individual subfield delineation together with 3D hippocampal surface projection of grey matter atrophy maps and demonstrate that patients with SCD show a differential pattern of atrophy of the hippocampal subfields mimicking that found in AD. A further study by Snitz and colleagues [14] reveals that older adults presenting to a memory clinic with concerns about their cognition, but testing within normal limits on objective evaluation, show measurable deviations on standardized scales of subjective cognition and negative affect and increased $\mathrm{A} \beta$ deposition on PiB-PET imaging compared with age-matched healthy controls recruited from the community.
Using a computer-based test, Koppara and colleagues [15] provide evidence for specific visual short term memory binding deficits in individuals with SCD and suggest that the results show that a feature binding test can help to objectify deficits in SCD which are not detectable with an established neuropsychological test battery.

Finally, Lista and colleagues [16] provide a comprehensive review addressing current perspectives and the way forward in SCD with emphasis on the issues of biomarkers.

The wide range of topics included in this special issue highlights how taking a 'division of labor' approach, i.e., by asking questions about a wide range of brain functions and behavior and using multimodal techniques to answer them, can significantly increase our understanding of this controversial and undeniably complex disorder. Although preliminary research into $\mathrm{AD}$ and mild cognitive impairment was typically limited to investigating a relatively narrow range of brain functions and behavior, mainly those assessed as part of clinical diagnosis, later research revealed that many more aspects and levels of brain function and information processing can be detrimentally affected. Already the findings included in this issue emphasize the importance of this approach, i.e., of asking new questions and finding answers by using multiple methodologies, in significantly improving our understanding of subjective cognitive impairment.

\section{REFERENCES}

[1] Stone J, Pal S, Blackburn D, Reuber M, Thekkumpurath P, Carson A (2015) Functional (psychogenic) cognitive disorders: A perspective from the neurology clinic. J Alzheimers Dis 48, S5-S17.

[2] Pennington C, Hayre A, Newson M, Coulthard E (2015) Functional cognitive disorder: A common cause of subjective cognitive symptoms. J Alzheimers Dis 48, S19-S24.

[3] Jenkins A, Tales A, Tree J, Bayer A (2015) Are we ready? The construct of subjective cognitive impairment and its utilization in clinical practice: A preliminary UK-based service evaluation. J Alzheimers Dis 48, S25-S31.

[4] Luck T, Röhr S, Jessen F, Villringer A, Angermeyer MC, Riedel-Heller SG (2015) Mortality in individuals with subjective cognitive decline: Results of the leipzig longitudinal study of the Aged (LEILA75+). J Alzheimers Dis 48, S33-S42.

[5] Tandetnik C, Farrell MT, Cary MS, Cines S, Emrani S, Karlawish J, Cosentino S (2015) Ascertaining subjective cognitive decline: A comparison of approaches and evidence for using an age-anchored reference group. J Alzheimers Dis $\mathbf{4 8 ,}$ S43-S55.

[6] Dalla Barba G, La Corte V, Dubois B (2015) For a cognitive model of subjective memory awareness. J Alzheimers Dis $\mathbf{4 8 ,}$ S57-S61. 
[7] Rabin LA, Smart CM, Crane PK, Amariglio RE, Berman LM, Boada, M, Buckley RF, Chételat G, Dubois B, Ellis KA, Gifford KA, Jefferson AL, Jessen F, Katz MJ, Lipton RB, Luck T, Maruff P, Mielke MM, Molinuevo JL, Naeem F, Perrotin A, Petersen RC, Rami L, Reisberg B, Rentz DM, Riedel-Heller SG, Risacher SL, Rodriguez O, Sachdev PS, Saykin AJ, Slavin MJ, Snitz BE, Sperling RA, Tandetnik C, van der Flier WM, Wagner M, Wolfsgruber S The Alzheimer's Disease Neuroimaging Initiative, Sikkes SAM, the subjective cognitive decline initiative (SCD-I) Working Group (2015) Subjective cognitive decline in older adults: An overview of self-report measures used across 19 international research studies. J Alzheimers Dis 48, S63-S86.

[8] Valech N, Mollica MA, Olives J, Tort A, Fortea J, Lleo A, Sánchez-Saudinós B, Molinuevo JL, Rami L (2015) Informants' perception of subjective cognitive decline helps to discriminate preclinical Alzheimer's disease from normal aging. J Alzheimers Dis 48, S87-S98.

[9] Rodríguez-Gómez O, Abdelnour C, Jessen F, Valero S, Boada $M$ (2015) Influence of sampling and recruitment methods in studies of subjective cognitive decline. J Alzheimers Dis $\mathbf{4 8}$ S99-S107.

[10] Archer HA, Newson MA, Coulthard EJ (2015) Subjective memory complaints: Symptoms and outcome in different research settings. J Alzheimers Dis 48, S109-S114.

[11] Yates JA, Clare L, Woods RT, Matthews FE The Cognitive Function and Ageing Study Wales (2015) Subjective memory complaints are involved in the relationship between mood and mild cognitive impairment. J Alzheimers Dis $\mathbf{4 8 ,}$ S115-S123.

[12] Buckley RF, Saling MM, Frommann I, Wolfsgruber S, Wagner M (2015) Subjective cognitive decline from a phenomenological perspective: A review of the qualitative literature. J Alzheimers Dis 48, S125-S140.

[13] Perrotin A, de Flores R, Lamberton F, Poisnel G, La Joie $\mathrm{R}$, de la Sayette V, Mézenge F, Tomadesso C, Landeau B, Desgranges B, Chételat G (2015) Hippocampal subfield volumetry and $3 \mathrm{D}$ surface mapping in subjective cognitive decline. J Alzheimers Dis 48, S141-S150.

[14] Snitz BE, Lopez OL, McDade E, Becker JT, Cohen AD, Price JC, Mathis CA, Klunk WE (2015) Amyloid- $\beta$ imaging in older adults presenting to a memory clinic with subjective cognitive decline: A pilot study. J Alzheimers Dis $\mathbf{4 8}$, S151-S159.

[15] Koppara A, Frommann I, Polcher A, Parra MA, Maier W, Jessen F, Klockgether T, Wagner M (2015) Feature binding deficits in subjective cognitive decline and in mild cognitive impairment. J Alzheimers Dis 48, S161-S170.

[16] Lista S, Molinuevo JL, Cavedo E, Rami L, Amouyel P, Teipel ST, Garaci F, Toschi N, Habert M-O, Blennow K, Zetterberg H, O'Bryant SE, Johnson L, Galluzzi S, Bokde ALW, Broich K, Herholz K, Bakardjian H, Dubois B, Jessen F, Carrillo MC, Aisen PS, Hampel H (2015) Evolving evidence for the value of neuroimaging methods and biological markers in subjects categorized with subjective cognitive decline. J Alzheimers Dis 48, S171-S191. 


\section{With support from:}

BRACE-Alzheimer's Research [Registered Charity 297965], Centre for Ageing and Dementia Research and OPAN, Swansea University, and Cardiff University

\section{College of Human and Health Sciences}

Coleg y Gwyddorau Dynol ac lechyd

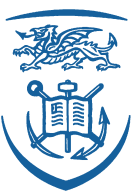

Swansea University Prifysgol Abertawe

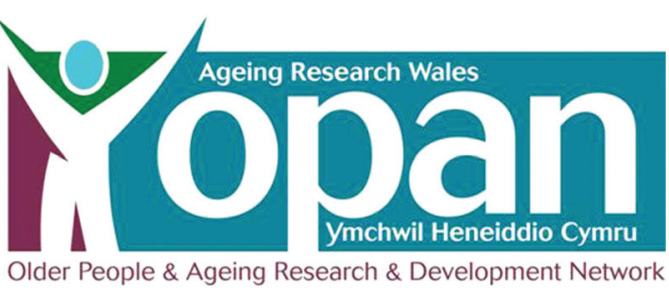

CARDIFF

UNIVERSITY

PRIFYSGOL CAERDYB

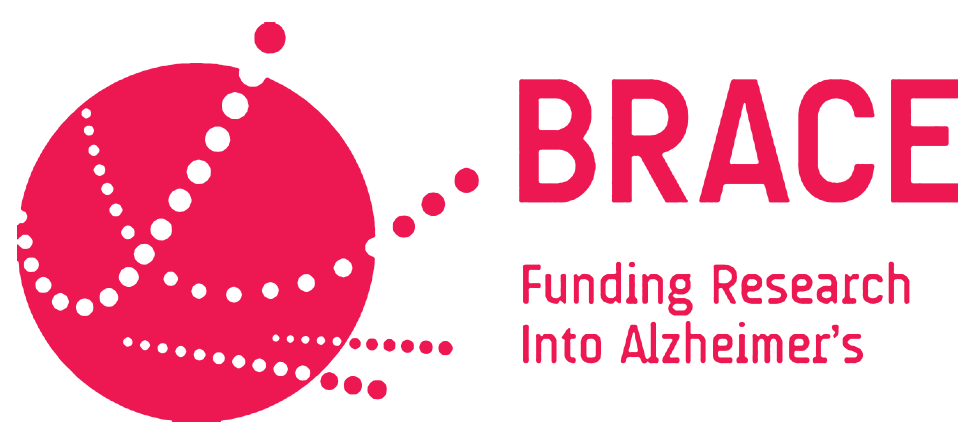

